\title{
Research
}

\section{Traditional Knowledge Systems and the Conservation of Cross River Gorillas: a Case Study of Bechati, Fossimondi, Besali, Cameroon}

\author{
$\underline{\text { Denis Ndeloh Etiendem }}^{1}, \underline{\text { Luc Hens }}^{2}$, and Zjef Pereboom ${ }^{3}$
}

\begin{abstract}
Traditional beliefs associated with the Cross River gorilla (Gorilla gorilla diehli) in Lebialem Division, Cameroon, were studied to establish the usefulness of incorporating these local belief systems into the conservation strategy for this critically endangered species. A survey was conducted in 2007 in five villages to assess local perceptions of human-gorilla totemic kinship practices and taboos against hunting and against eating of gorillas. Villages were selected based on their proximity to Cross River gorilla $(\mathrm{CRG})$ habitat, with a total of 184 interviewer-administered questionnaires completed during a 4-week period. Eighty-six percent of people agreed that gorillas were totems (personal spiritual helpers or counterparts) of people living in the village. People who believed in human-gorilla totemic kinship practice did not eat or hunt gorillas, and they wanted gorillas to be protected in order to protect the practice. Most $(87 \%)$, of the interviewees declared their support for gorilla conservation. The main motivation was the belief that when gorillas are killed, the human totemic counterpart will die as a result. Because of these traditions, the hunting of gorillas is taboo in all five villages surveyed. On the other hand, gorilla parts play a direct role in traditional medicine, and gorilla bones are valued as ingredients for traditional medicine. Also, general awareness and adherence to local totemic practices was found to be declining, particularly among young people (18-25 years). Despite the imminent decline in value of belief systems that led to the establishment of the hunting taboo, this taboo is still in place and has discouraged the hunting of gorillas. Where law enforcement is weak or near inexistent, these traditional restrictions could be critical to the continuing survival of a gorilla population. Reviving and promoting beliefs and practices conducive to gorilla conservation could foster positive attitudes and behavior and have the potential to encourage local support and participation in communities. However, care must be taken when selecting practices to promote, as some (for example the use of gorillas in traditional medicine) could encourage the killing of animals.
\end{abstract}

Key Words: Cameroon; critically endangered; traditional knowledge; village

\section{INTRODUCTION}

The survival of endangered species and ecosystems depends on long-term participation and understanding of local populations (Oates 1999). Because of the close relationship between cultural diversity and biodiversity, traditional knowledge systems should play an important role when developing species conservation and management strategies (Caldecott et al. 2005, Hens 2006). For example, the United Nations Convention on Biological Diversity (UNCBD) (article 8j) calls for parties to respect, preserve, and apply knowledge and practices of indigenous and local communities relevant for the conservation and sustainable use of biodiversity
(UNCBD 2007). Despite these recommendations, few studies have investigated traditional beliefs concerning endangered primates and how they could be integrated into conservation strategies (but see Saj et al. 2006). Many African cultures hunt and eat apes and other smaller primates, and hunting remains the greatest threat to primate survival in the wild in many areas. However, some of these primate species in addition to their food value also play an important role in African traditional mythologies and forest region beliefs (Terashima 2001, Hens 2006, Saj et al. 2006, Charnley et al. 2007, Osemeobo 2001). For example, the exploitation of some primate species in Africa is largely prohibited because local communities adorned them with ritual 
meanings, regard them as animal totems, or value them as fetishes or aids to traditional medicine practice (Osemeobo 1991, Adams and McShane 1996). In addition, traditional knowledge in the form of local taboos that restrict or regulate the exploitation of wildlife is thought to have contributed significantly to preventing the extinction of some wild primates (Rose et al. 2003). Unfortunately, present indicators show that these practices are generally on the decline in most parts of Africa (Hens 2006) due to changes in the belief systems of people with regard to the spread of new influences (e.g., Christian sects).

In Cameroon, much of the country's biodiversity has been in the hands of rural groups, societies of hunters and farmers, herders, and fishermen for many generations. Traditional knowledge is still very prominent in most remote areas, where decisions about exploitation of local natural resources are heavily influenced by traditional authorities. In these areas, traditional institutions are central to the management of common resources, such as wildlife in unprotected communal forests. In some cases, the exploitation of species that have a material or spiritual relationship with the community is often regulated. However, traditional beliefs and practices related to primates and recorded in Cameroon have not always carried a positive potential for the conservation of these species. For example, Critchley (1968) reported the use of apes (gorillas and chimpanzees) in traditional medicine and as fetishes. Even today, those who own bones or skulls of these animals are respected traditionally, and in some cases, are given chieftaincy positions within community social structures.

The Cross River gorilla (CRG), Gorilla gorilla diehli, is listed as critically endangered by the International Union for Conservation of Nature (IUCN; Mittermeier et al. 2009). It is the most endangered sub-species of the Western gorilla, Gorilla gorilla, and is arguably the most endangered great ape in the world. The entire CRG population is thought to be as low as 190-202 individuals fragmented across ca. 12 hilly sites along the Cameroon-Nigeria border (Nicholas et al. 2010). The human population density within the CRG distribution is one of the densest in Africa, with more than 100 people per $\mathrm{km}^{2}$ in some places (Oates et al. 2004). Consequently, human activities greatly threaten CRG survival. The major threats to CRG existence include, but are not limited to, forest loss, habitat fragmentation, and timber exploitation. The CRG have been hunted heavily in the past (Bergl 2006) and, although hunting seems to have subsided, any minimal level of off-take could be detrimental to the survival of the remaining population (McFarland 2007). Gorillas are protected by law across their range, however, enforcement is inadequate. In Cameroon, for example, although the 1994 Law on Forests, Wildlife and Fisheries (Law 94/01) and the supporting decrees on wildlife issued in 1995 (Egbe 2001, Caldecott et al. 2005, Taah et al. 2005) prohibits the killing of gorillas, prosecutions are rare.

Whereas gorilla tourism elsewhere has become a lucrative tool in fostering community support and participation in conservation, habituating Cross River gorillas to tourists presents particular challenges. First, these gorillas have been heavily hunted until recently and are, therefore, wary of humans. Second, they live in small pockets of dense vegetation forests in areas that are rugged and mostly inaccessible. Therefore, although tourism might be recommended for some individual groups in the future, plans for CRG tourism must be evaluated with great care, with full consideration given to all risks to the species.

The objective of this study is to record and present traditional beliefs and practices concerning CRG; this paper discusses the usefulness of incorporating such beliefs and practices into the conservation of the species. The aim is to: (1) understand traditional beliefs and practices associated with gorillas; (2) assess the importance and limits of integrating these beliefs and practices into gorilla conservation strategies; and (3) propose recommendations accordingly. In addition, this paper will serve as a historical document of the fast-disappearing traditional knowledge of the study villages.

\section{METHODS}

\section{Study Site}

The study was conducted in five villages around the Bechati-Fossimondi-Besali (BFB) forest $\left(5^{\circ} 37^{\prime}-5^{\circ}\right.$ $42^{\prime} \mathrm{N}$ and $9^{\circ} 53^{\prime}-9^{\circ} 58^{\prime} \mathrm{E}$ ) in the Lebialem Division, South West Region, Cameroon (Fig. 1). These five villages are located close to the forest and claim joint ownership of the forest. Currently, this forest has no legal management status and is classified as 
Fig. 1. Location of study areas showing continental, provincial, and village location. Map produced with assistance of WCS-TMLP.
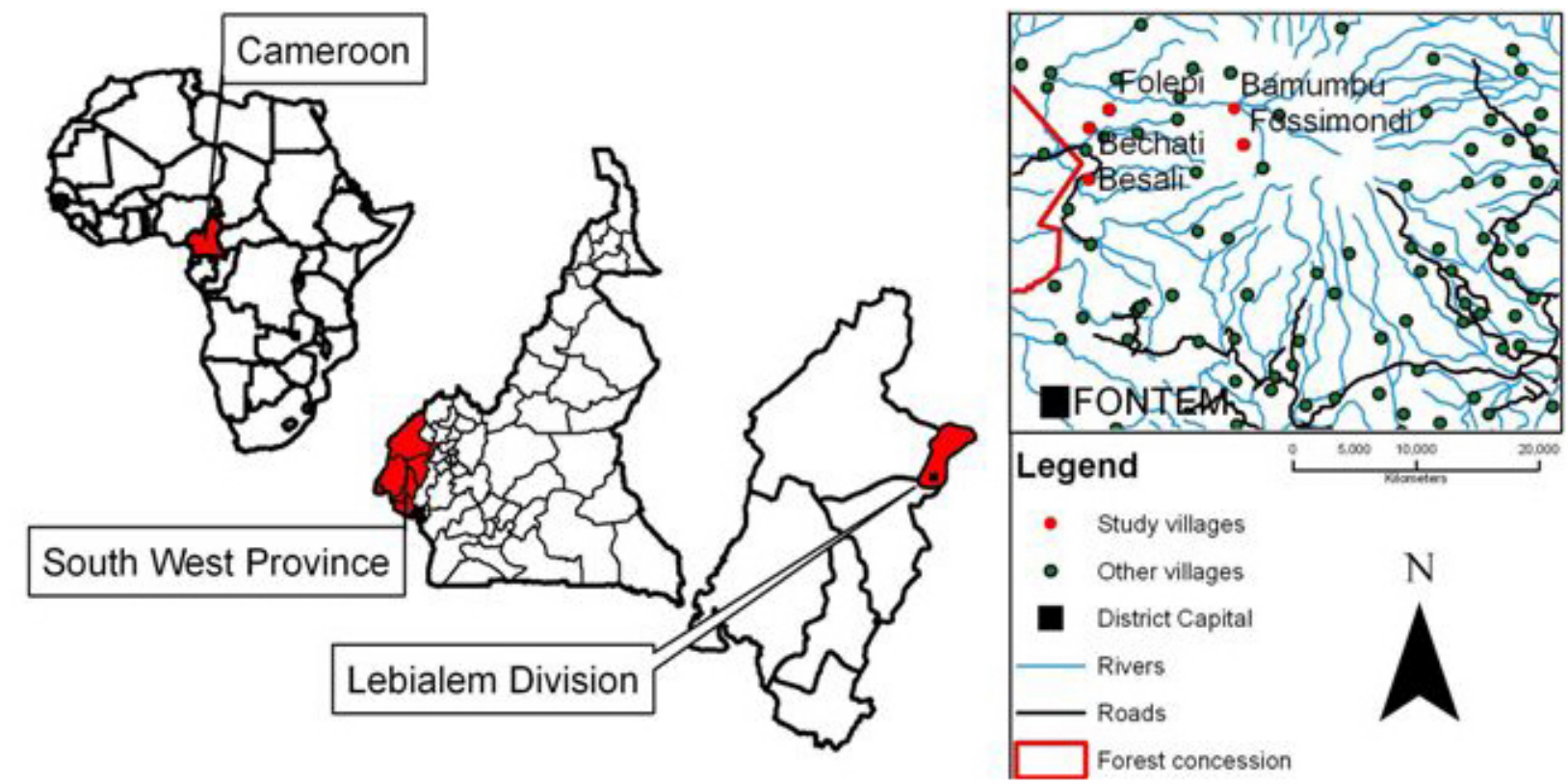

"communal forest" under the Cameroonian Forest Code Law no. 94 of 20 January 1994. The human population of the study area is estimated to be 7,000 inhabitants (Nkembi et al. 2006; Nkembi et al., unpublished report). The topography is rugged with steep hills and valleys. The climate is humid, with an annual temperature range of between $21^{\circ} \mathrm{C}$ and $26^{\circ} \mathrm{C}$.

The Cameroon highlands region in which this forest is located is an area of rich species diversity (Comiskey et al. 2003, Oates et al. 2004). The mosaic of forest types of the BFB forest (ranging from lowland through mid-elevation to savanna forests) provides various habitats that support a high biodiversity (Nkembi et al. 2006). The forest is used for different reasons, ranging from agricultural expansion, hunting, fishing, collection of nontimber forest products (NTFPs), and harvesting of timber for fuel wood and construction. Non-timber forest products are mainly harvested for subsistence, but some products such as "bush mango" (Irvingia gabonensis) and Eru (Gnetum spp.), are also traded in the local market. Forests are also used to plan and prepare rituals for the enthronement of traditional rulers and for many other community cleansing activities. Throughout the study villages, political authority is vested in a village chief, who is supported by a traditional council, and is called Fon (Brain 1967). Chiefs are enthroned by traditional ritualistic sacred societies and installed by the political administration (Atem 2000). Social facilities such as pharmacies, health clinics, electricity, and piped water are largely absent, and people rely heavily on traditional healers for medical care. Most diseases are believed to be caused by sorcery and/or loss of ancestral protection. Catholic, Presbyterian, and Full Gospel churches among others have a representation in most of the study villages. Despite the proliferation of these churches, traditional religions play a central role in the spirituality of the people (Atem 2000).

\section{Data Collection and Analysis}

Data for this study were obtained through an interviewer-administered questionnaire survey conducted over 4 weeks in July and August 2007. The first aim of the survey was to explore respondents' knowledge of gorillas and investigate their awareness of, and attitudes toward, traditional taboos and totemic beliefs associated with gorillas. Secondly, respondents' perceptions of the power 
and influence of traditional beliefs and practices on the protection of gorillas were explored. We purposefully sampled five villages (Bechati, Besali, Bamumbu, Fossimondi, and Folepi) based on their proximity to the gorilla habitat (BFB forest) and the high levels of dependence on this forest for livelihood by people from these villages (see Nkembi 2006; Nkembi et al., unpublished report). These five villages claim to be the owners of the BFB forest, and people from other villages are not allowed to hunt or collect resources from this forest without permission.

Two research assistants (recently graduated school teachers from Yaoundé) were recruited and trained to assist the senior author in conducting the survey. This was tested during a 2-day pilot study. In each village, a systematic random sampling technique was used to select participants to be interviewed. Households along village paths were randomized by sampling every second household encountered as the interviewer moved through the village. At the beginning of each interview, informants were briefed on the subject and objectives of the research. Interviews were conducted in Pidgin English (a language similar to English and used in Englishspeaking regions of Cameroon) and took approximately 25 minutes. Adult men, women, and youths were targeted. In each household, one adult and one younger family member were interviewed. From 220 interviews attempted, there were 184 valid questionnaires, an average of 37 questionnaires administered per village (14-59). In total, there are about 500 households in the study villages. Initial analysis indicated very little difference between villages for most responses, and because of this, data from all five villages were pooled during the analysis. Basic frequencies were calculated for all categorical data produced. Data were analyzed using cross tabulation with chi-square analysis $(2 \mathrm{x}$ 2 contingency tables, two-tailed). Kruskall Wallis $\mathrm{H}$ test was used to identify relationships between dependent and independent variables. The significance level was 0.05 for all statistical tests. We used the software package PASW Statistics (v18.0), and Excel (v9).

\section{RESULTS}

\section{Demography}

From a total of 184 interviews, the majority of participants were men $76 \%(n=140)$ compared with $33 \%$ women $(n=44)$. Most respondents were older than $55(29 \%)$, with the remainder between the ages of 26-35 years $(24 \%), 36-45$ years $(6 \%), 46-55$ years $(15 \%)$, and $18-25$ years $(13 \%)$. Nearly half the population $(55 \%)$ had attended primary school. Twenty-three percent of the population had been to secondary school, $6 \%$ attended university, and $16 \%$ had no formal education. Men showed a slightly higher level of literacy than women in each group: "no formal education" (18.2\% among women vs. $15 \%$ among men); "secondary education" (25.7\% among men vs. $15.9 \%$ among women); and "university education" (6.4\% among men vs. $4.6 \%$ among women). Up to $83.3 \%$ of the sample population had lived in their present villages for more than 10 years. The major livelihood activity of respondents was farming (64\%). The next most common livelihood activity was grouped under "artisan", referring to activities such as carving, tailoring, building, woodwork, and other technicians (19\%). Only a very low proportion of income came from other sources such as hunting and traditional medicine $(6 \%)$. The majority of the respondents reported consuming fish as their main source of animal protein $(76 \%)$. Bushmeat $(9 \%)$ and pork (7\%) were not frequently consumed. As reported, the choice of fish was based on availability (fishing along numerous small streams that run through the villages), and lower cost compared with alternatives. Bushmeat from the forest is considered a delicacy but is not reliable because the probability of a catch is based on hunter effort and, more so, because over harvesting had drastically reduced the abundance of wildlife around the villages. Seventyfive percent of the respondents were currently married and $20.7 \%$ single. The unmarried population mainly represented the youths sampled.

\section{People's Knowledge of Gorillas}

The vast majority of respondents $(97 \%)$ were aware of the presence of gorillas in the forest around their village, however, only $38 \%$ of respondents could accurately describe a gorilla as a large black and hairy animal, with a black face; no tail; that walked on four limbs; and upright occasionally. Thirty-two percent $(n=60)$ of respondents said they have seen gorillas in the forest. The relationship between those who claimed to have seen gorillas in the forest and those who reported as hunters was significant $\left(\chi^{2}=\right.$ $4.990, p<0.05, \mathrm{df}=1)$. Older people $(>55$ years of age) could more accurately describe gorillas than younger ones, but this difference was not significant $\left(\chi^{2}=5.014, p>0.05, \mathrm{df}=4\right)$. 
Table 1. Perception of totemic kinship practices with gorillas among interviewees in five villages of Lebialem Division, July 2007.

\begin{tabular}{lccc}
\hline \hline Statement about totemic kinship belief & Disagree & Neutral & Agree \\
\hline Village people use gorillas as totem animals & 2 & 11 & 86 \\
If a gorilla is killed the totem owner dies as well & 1 & 10 & 88 \\
Traditional healers use gorilla totem animals to harvest plants & 1 & 19 & 80 \\
The practice of totemic kinship with gorillas is not good & 41 & 14 & 45 \\
Lets protect gorillas to save animal totem owners & 3 & 9 & 88 \\
Lets encourage our children to have/use gorillas as totem animals & 71 & 11 & 18 \\
\hline
\end{tabular}

\section{Totemic Beliefs and Taboos about Gorillas}

Overall, $86 \%$ of respondents "agreed" with the statement that "gorillas are used by local people as totem animals" (Table 1). Although gorillas were the main focus of these totemic kinship beliefs, some respondents also mentioned the use of chimpanzees, monkeys, leopards, brush-tailed porcupines, and owls as animal totems. The belief that if a gorilla is shot and killed, the totem owner will also die was very popular-90\% "agree" response (Table 1). A lot of stories were told of hunters who shot and killed a gorilla, and afterward discovered that a person from the village, or the neighboring village, had died as a result of the death of his/her totemic counterpart (some of these stories are reported in Etiendem 2008). However, a traditional healer in Besali testified that the totem owner will only die if he/she does not seek immediate traditional medical attention. Eighty-eight percent of the respondents agreed that gorillas should be protected so as to protect people using gorillas as a totem animal. The other $12 \%$ did not link the protection of gorillas to these totemic beliefs (Table 1). Contrarily, many people, even after acknowledging the existence of totemic association between humans and gorillas and supporting the protection of gorillas in order to protect these people, did not think that these practices should be encouraged in the future. For example, responses to the statement "the practice of totemic kinship with gorillas is not good" revealed that respondents were almost equally split between "disagree" (41\%) and "agree" (45\%). Fourteen percent remained neutral, and the difference in response between men and women was significant (Kruskal-Wallis: $\chi^{2}=6.142, p<0.05, \mathrm{df}=1$ ).

This was further demonstrated when $72 \%$ of respondents said they may not encourage their children to practice totemic kinship with gorillas. According to one of the respondents, children should not be encouraged to practice totemic kinship with gorillas not because the practice is bad, but because "children are more careless and will unknowingly expose themselves to hunters if they take up the practice" (Anonymous). Young people (16-25 years old) were less inclined to support youth involvement in gorilla-totem practices than older people ( $>55$ years old) $(95.8 \%$ c.f. $64.0 \%)$.

\section{Gorilla Taboo Culture}

Fifty-six percent $(n=103)$ of respondents were aware of the existence of taboos against hunting and eating gorillas in their village. Most of the respondents who affirm the presence of taboos were older than 55 years. For $69 \%$ of those who testified to the existence of a taboo against hunting and eating gorillas, this taboo was in place before they were born. Others said the taboo was instigated "a few years ago" $(27 \%, n=28)$, or "more than 10 years ago" $(3.8 \%, n=4)$. Nearly all interviewees $(97 \%$, $n=100$ ) affirming the presence of taboos said that taboos are still respected. It was reported that taboos are mainly enforced through traditional councils. 
Defaulters are either punished by automatic spiritual sanctions, such as falling ill and/or dying, or other sanctions meted out by the chief or traditional council elites. The chief of Besali village reported that people who hunt gorillas, or chimpanzees, can be punished by one of the following mechanisms: (1) disbanded from taking part in communal functions; (2) exiled from the community; or (3) forced to perform some rituals or pay a fine.

In addition to the village restriction, some respondents also highlighted personal reasons why they do not hunt or eat gorillas. Some of these were: (1) morphological similarities between humans and gorillas. For example, one woman stated that she cannot eat an animal that looks exactly like a human. (2) Respondents' age and village social status. For example, it was reported that women of childbearing age are particularly prohibited from eating gorillas because of the belief that if they do, they will give birth to gorilla-like babies. (3) Gorillas are used as animal totems. For example, one woman in Bamumbu said: "eating an animal that is used by a fellow human as totem can bring ill luck to an entire family." In Bechati and Besali villages, this taboo also restricted the killing and eating of chimpanzees. The taboo did not extend to other aspects beyond hunting and eating of the species.

Additionally, fear of a particular species can offer a tangible explanation as to why people will avoid it. The majority of respondents admitted that they fear gorillas $(91 \%, n=168)$. This fear is probably motivated by the animal's physical appearance and superstitious beliefs about it. Eighty-nine percent ( $n$ $=150$ ) of those who admitted that they fear gorillas added that they do so because gorillas are used by people as totems.

\section{Hunting Gorillas}

Forty percent ( $n=74$ ) of the interviewees reported that they are hunters (this includes hunting with guns and traps). Most of these were men (66 vs. eight women). Only three hunters admitted to having killed gorillas. The last gorilla hunting incident reported was carried out more than 15 years ago. The reasons given for not hunting or killing gorillas varied (Fig. 2). The most common reason was the local traditional beliefs and taboos related to gorillas (41\%, $n=29)$. Hunting difficulties $(22 \%, n=16)$, which referred to the inability of hunters to obtain suitable guns and cartridges, was the next most commonly reported factor. Hunting difficulties were, however, a secondary reason why people don' thunt gorillas and, as they put it, "even if gorilla hunting was not prohibited, it would still have been difficult to hunt them because of lack of proper guns and/or cartridges." Wildlife laws were reported to have minimal influence in restricting hunting of gorillas (Fig. 2).

\section{Gorillas and Traditional Medicine}

In the absence of medical facilities, a considerable number of people living in the study area rely on traditional medicines. In addition, many diseases are perceived to be caused by loss of ancestral protection and can only be cured by traditional medicine. Thirty-six percent $(n=66)$ of the respondents said that gorilla body parts have medicinal value, $57 \%(n=105)$ did not think gorilla parts have medicinal value and $7 \%(n=13)$ did not know. Comparing this response against the age of the respondents showed that $46 \%$ of those who agree that gorilla products have medicinal value are people older than 55 years $\left(\chi^{2}=22.419, p<0.05\right.$, df $=8)$. When asked what parts of gorillas were used for medicine, respondents cited: skulls, other bones, dung, heart, and hairs (Fig. 3). The respondents considered mental illness, rheumatism, impotence and bone fractures to be the main diseases curable by medicine with some form of gorilla ingredient (Fig. 4). There also existed a strong perception that the bones of gorillas are very useful as an antibiotic to make children strong. A hunter in Besali showed off a gorilla femur bone that he claims to use in curing human diseases. When asked the source of that particular bone, he claimed that it was handed down to him by his father more than 20 years ago. The thickness of this bone was greatly reduced due to constant scraping. In addition to the use of gorilla parts in traditional medicine, most respondents believed that traditional medicine men transform into gorillas to harvest leaves from high canopy forest trees ( $80 \%$; see Table 1). Of the $36 \%$ of respondents $(n=66)$ who admitted that gorillas are used in traditional medicine, only $38 \%(n=25)$ said that the same diseases could be treated in a hospital. Traditional medicine is highly regarded in the study area, with twice as many interviewees reporting that they would consult a traditional healer rather than seek the services of a medical doctor (46\% cf. $23 \%$ ). This is largely because modern medical facilities are absent in the area and may not refer to the 
Fig. 2. Reasons for not hunting gorillas as reported by hunters in five villages in Lebialem Division, July 2007 (percentage of respondents who reported themselves as hunters, $n=71$ ).

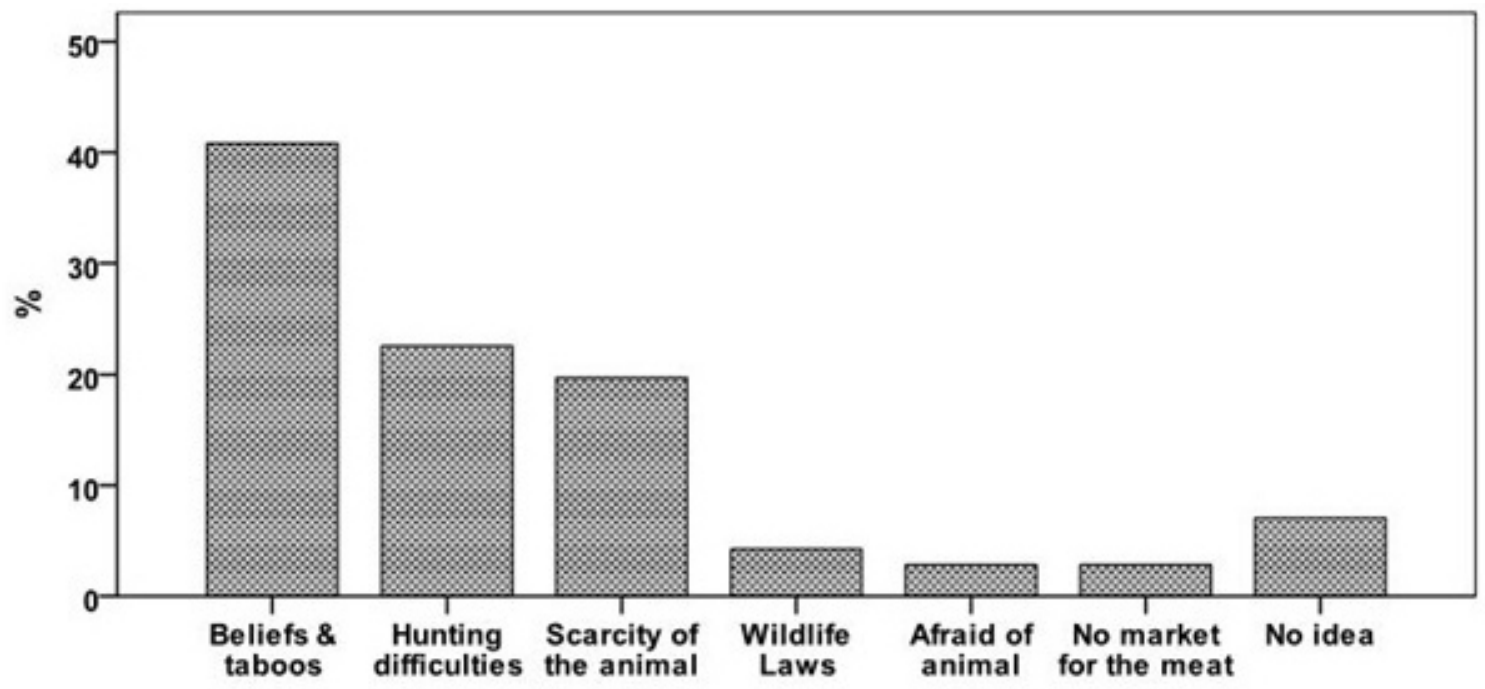

superiority of one practice over the other. Some people opted for combining both systems. There was a general feeling among the respondents that traditional medicine practice is declining.

\section{Conservation of Gorillas}

The majority of respondents $(87 \%)$ said they support gorilla conservation as opposed to just $13 \%$ who did not (Table 2). Totemic belief was the main reason why people wanted to see gorillas alive (Table 2). On the other hand, people who did not support gorilla conservation mentioned crop raiding and gorillas' hostility to humans as reasons.

\section{DISCUSSION}

This study indicates on the one hand, that as a result of totemic kinship beliefs associated with gorillas, active hunting and eating of the species are avoided through species-specific taboos; and on the other hand, that these belief systems are eroding and, if not revived, could disappear, with potential consequences for the survival of the species. When confronted with these circumstances, it is easy for conservationists to ignore local belief systems and stick to more contemporary systems, as it can be argued that traditional belief systems are losing ground and incorporating them into conservation strategy is meaningless as the beliefs will eventually disappear.

Cross River gorillas have been listed by the IUCN since 2007 as critically endangered. Moreover, their remaining habitats are isolated and highly fragmented. Conservationists have emphasized that the survival of population located outside protected areas (such as the Bechati-Fossimondi-Besali population) will ultimately depend on the involvement of local communities living adjacent to these populations (Oates et al. 2007). In such places where the conservation of endangered animals urgently needs the support of local communities, traditional knowledge of wildlife is crucial (Nyhus et al. 2003), and until these belief systems completely disappear, integrating them into conservation strategies is vital to the day-to-day survival of the species they protect.

The extent to which the human-gorilla totemic association was emphasized throughout the study area revealed its importance to people's cultural and religious values. Most respondents believe that if the totem gorilla is killed, the human counterpart 
Fig. 3. Gorilla body parts reported as ingredients for traditional medicine in five villages of Lebialem Division (percentage of all respondents).

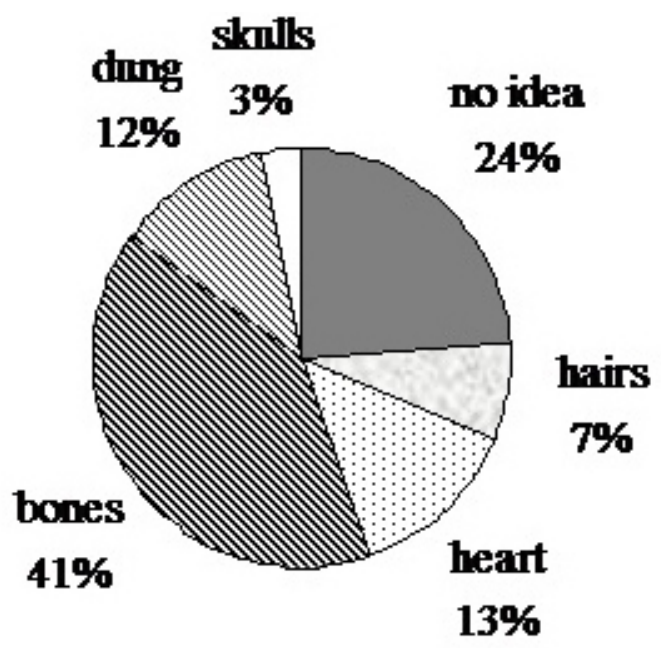

also dies unless he/she seeks immediate disconnection from the soul of the deceased totem by treatment from a traditional healer. The fear of human death resulting from the death of gorillas seems to be the strongest reason why people do not want to hunt the species. One woman in Bamumbu testified that: "Killing gorillas means taking away very important people from my village and I am totally against it even though gorillas did raid my farm." Although human-gorilla totemic kinship practices are still popular within the study area, the practice itself seem to be waning. For example, most people interviewed did not want to encourage their children to have/use gorilla totems saying it is no longer safe to do so. Additionally, the youths interviewed seemed to be less knowledgeable about their traditions than their elders. Such a reduction in the respect and practice of traditions protecting wildlife will not only reduce its applicability in conservation strategies but puts the survival of the species at risk unless the people are actively introduced to and sensitized about modern-day conservation needs and benefits as a replacement.

In all villages surveyed, gorilla hunting is taboo. Although the origin of this taboo could not be reliably established, one elderly respondent asserted that the taboo was established by traditional rulers who personally used gorillas as their animal totems. Largely because of this taboo, no gorilla hunting incident has been reported in the area in the past 15 years. The presence of taboo prohibiting exploitation of the species has been considered elsewhere as a successful local conservation strategy (Colding and Folke 2001, Banjo et al. 2006, Saj et al. 2006). However, if not revived, the loss of respect for the beliefs and practices that led to the taboo is imminent. But it is equally important to note that these taboos are currently still in place and are largely respected. A similar taboo system within the CRG range (e.g., the case of Kagwene Mountains -Ymke Warren, pers. comm.) has been described as critical to the continuous survival of the species there.

Experience from the area has shown that the revival of a fading belief system is not impossible. In Fossimondi, for example, respondents testified that the taboo was already dying out but was reinstituted due to the influence of a local conservation organization known as ERuDeF. This is an excellent example where the presence of conservationists leads to the revival of a taboo system that was almost lost and shows that the protection of gorillas in this area is at its best when the traditional and modern approaches are combined. [ERuDeF is a wildlife conservation organization working to protect great apes in the study area since 2004. In addition to ecological surveys, awareness raising, and law enforcement, ERuDeF works closely with local 
Fig. 4. Diseases reported to be cured by traditional medicines containing gorilla parts in five villages of Lebialem Division (percentage of all respondents).

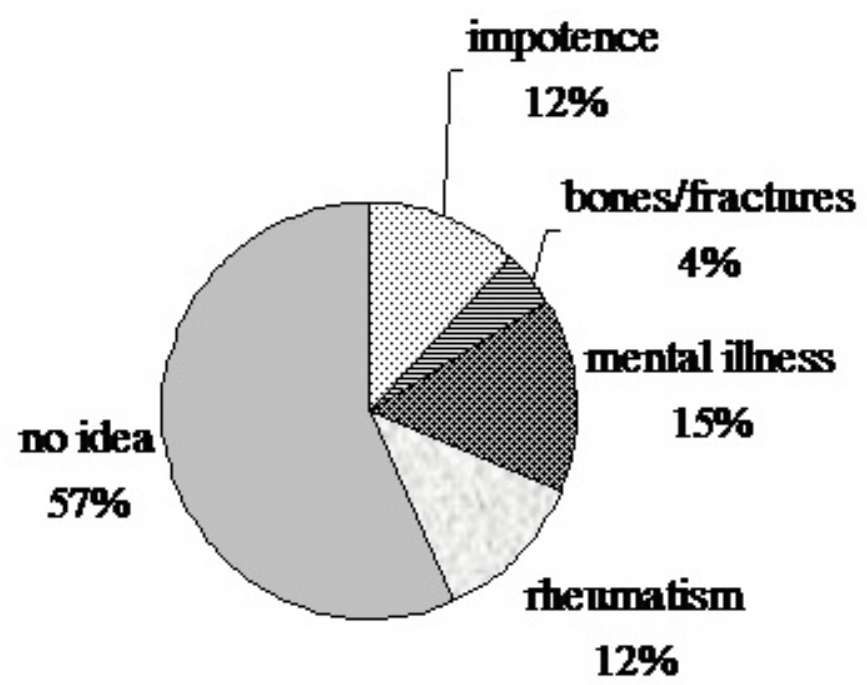

traditional institutions and promotes the enforcement of hunting and eating taboos in villages where such taboos exist.]

The rejuvenation (this study) or establishment of new hunting bans (Saj et al. 2006) can no doubt contribute to the protection of endangered species in more forests. Previous studies (Wright 2007) indicate that $28 \%$ of the people in Fossimondi, 35\% of the people in Bechati, and $42 \%$ of the people in Besali are ignorant of the wildlife law that prohibits the killing of gorillas and other wildlife. Thus it seems likely that a good proportion of hunters in the BFB forests conserve gorillas not because it is the law, but because of traditional beliefs and taboo. Regulations based on traditional customs and sanctioned by traditional institutions are often more likely to be respected than those imposed by distant and ineffective government institutions (Colding and Folke 1997).

However, not all practices associated with gorillas at BFB forest can be linked to a positive conservation function. For example, gorilla parts are still used in traditional medicine. Even though the practice is declining, and a single bone might be used for many decades before replacing, the population of the CRG is so small that the loss of a single animal could have serious consequences on the genetic survival of the sub species (Bergl 2006).
In addition, the use of gorilla skulls as fetishes is not practiced in this area even though it has been reported in neighboring CRG sites (Critchley 1968, Ekinde et al. 2005; Bucknell and Groves, unpublished report). This difference in belief systems across sites certainly limits the generalization of results across sites - a reminder that integration of local knowledge system into conservation strategy must be case specific.

Many authors (Gadgil et al. 1993, Colding and Folke 1997, Berkes 2004) have argued that learning from and using traditional knowledge of local communities not only build the much needed consensus between conservationists and local people but give communities a sense of ownership of wildlife management projects and programs. Nevertheless, conservation of gorillas without conservation of the forests in which they exist will mean their eventual demise. For example, taboos on hunting certain monkey species in the BoabengFiema Monkey Sanctuary (Ghana) did not necessarily translate into conservation of other wildlife, or the protection of the forest in which the monkeys lived (Saj et al. 2006). Thus, we suggest that traditional beliefs to protect gorillas need to be integrated with modern ecosystem knowledge to present people with an ethos that protects not only the gorillas and their forests, but also the valuable ecosystem services upon which people in such 
Table 2. Response to the question "Should gorillas be protected" by villagers in the Lebialem Division of South West Region, Cameroon (percentage of all respondents, $N=184$ )

\begin{tabular}{llc}
\hline \hline Ranked reasons why gorillas should be/not be protected & Percentage \\
\hline Yes & They are totem animals & 30 \\
We want the next generation to also see them & 23 \\
& Important for medicine & 11 \\
& Gorillas visitors will bring development to the village & 8 \\
& Important to the forest ecosystem & 4 \\
& Similarity to humans & 1 \\
& We need more in the future for hunting & 2 \\
No idea & Gorillas are dangerous and can kill humans \\
& Gorillas raid crops \\
Totemic practice is not good and totem animals should be killed & 5
\end{tabular}

poorly developed rural areas rely for their everyday existence. On the basis of this argument, the following recommendations are proposed:

1. In raising awareness about the need to conserve gorillas in the study area, traditional channels of knowledge transmission could be used to make the conservation message more acceptable locally. For example, fora through which elderly people narrate folk tales to younger people about gorillas can teach youth of their historical relationship with the species and help generate passion for the species. Such fora should be encouraged throughout the region, and knowledgeable elders motivated to act as channels for the transfer of gorilla knowledge to children.

2. Traditional belief systems could be greatly revived by documenting and promoting the use of folk tales about gorillas and other wildlife in the local and national school system. There are stories that warn listeners of the potential mystical consequences of attempting to hunt gorillas. Other stories portray the human-like, gentle, and understanding nature of gorillas. These stories have been fundamental in generating a local conservation ethic in the study region that inspires some people to adopt personal taboos against hunting or eating gorillas. If these stories are promulgated to a wider audience through the national curriculum, they could potentially motivate more people to adopt such personal use restrictions.

3. In areas where effective taboos and other traditional wildlife enforcement mechanisms are in place, they should be integrated into the wildlife law. Traditional councils need to be partners in successful wildlife management efforts in remote areas. The inclusion of the taboo system that encourages protection into wildlife management not only helps to protect the species in question but also protect the knowledge system from disappearing. This is most important in very remote areas such like Bechati-Fossimondi-Besali where implementation of wildlife laws has not been very effective. 
4. Traditional beliefs and practices concerning gorillas presented in a non-directive way represent an important social, ethical, and historical fact about the relationship between humans and non-human primates, irrespective of its alignment with scientific insights on gorilla conservation. The documentation of such knowledge systems should be encouraged and extended to other primate and non-primate taxa.

\section{CONCLUSION}

The cultural transformation taking place throughout Africa has undoubtedly put into question the validity and power of integrating local belief systems pertinent to primate species into the conservation agenda. Yet holders of these knowledge systems remain vital stakeholders in primate conservation, particularly in unprotected forest areas. Villagers living around the BechatiFossimondi-Besali forests still appear to recognize and respect traditional beliefs regarding gorillas. However, interest and support of such traditional cultures is eroding fast as these villages become more globalized. Thus, the loss of traditional knowledge concerning wildlife in this area is imminent. This could have negative consequences for CRG conservation in some parts of Cameroon; particularly, in those areas where law enforcement is near absent and taboos are the only reason why gorillas are not actively hunted. Reviving and incorporating into modern-day conservation strategies local traditions that respect and protect gorillas could not only help conserve the species, but also the traditional culture of the BechatiFossimondi-Besali communities. In local contexts where cultural perceptions and traditions toward gorillas lean toward the positive, using traditional knowledge to foster positive attitudes and behavior is an approach that has the potential to stimulate gorilla conservation in communities. However, care must be taken when selecting practices to revive or promote, as some (for example encouraging the use of gorilla skulls and bones in traditional medicine) could be misinterpreted as calling for the killing of animals.

New and holistic wildlife conservation policies that blend traditional systems of regulation, myths, rituals, and perception with existing administrative legislation are recommended to enhance conservation programs in this area. Greater collaboration between conservationist/wildlife managers and traditional institutions (e.g., village councils) responsible for regulating and enforcing taboos where such taboos exists should be a core priority of conservation efforts aimed at gorillas.

Responses to this article can be read online at: http://www.ecologyandsociety.org/voll6/iss3/art22/ responses/

\section{Acknowledgments:}

We are indebted to the late Dr. Ymke Warren for her bravery, hardwork and inspiration. Her words of encouragemt to young people seeking a career in wildlife conservation will forever be missed. We love you YM. We are sincerely grateful to all those who contributed to the success of this study. We would like to thank the field assistants Mr Ncha Edwin and Miss Melanine Tamjong, the traditional leaders and villagers of all the villages visited, and the administrative authorities of Lebialem, whose permission enabled the survey to go ahead as planned. Special thanks go to the Vlaamse Interuniversitaire Raad - University Development Cooperation (VLIR-UOS), as well as Conservation International and IDEA WILD for funding this project.

\section{LITERATURE CITED}

Adams, J. S., and T. O. McShane. 1996. The myth of wild Africa: conservation without illusion. University of California Press, Berkeley, California, USA.

Atem, G. 2000. The Fontem Kingdom [sic]: a brief history and tradition of Lebang people. ANUCAM Publishers, Bamenda, Cameroon.

Banjo, A., G. Otufale, O. Abatan, and E. Banjo. 2006. Taboo as a means of plant and animal conservation in south-western Nigeria: a case study of Ogbe river and its basin. World Applied Science Journal 1:34-43. 
Bergl, R. A. 2006. Conservation biology of the Cross River Gorilla (Gorilla gorilla diehli). Dissertation. Graduate Center, City University of New York, New York, New York, USA.

Berkes, F. 2004. Rethinking community-based conservation. Conservation Biology 18:621-630.

http://dx.doi.org/10.1111/j.1523-1739.2004.00077. $\underline{\mathrm{X}}$

Brain, R. 1967. The Bangwa of west Cameroon: a brief account of their history and culture. University College of London, London, UK. [online] URL:

http://www.lebialem.info/The \%20Bangwa\%20of\% 20West\%20Cameroon.pdf.

Caldecott, J., L. Mills, and C. Nelleman. 2005. Challenges to great ape survival. Pages 217'234 in J. Caldecott, and L. Mills, editors. World atlas of great apes and their conservation. University of California Press, Los Angeles, California, USA.

Charnley, S., A. P. Fischer, and E. T. Jones. 2007. Integrating traditional and local ecological knowledge into forest biodiversity conservation in the Pacific Northwest. Forest Ecology and Management 246:14-28. http://dx.doi.org/10.1016/ j.foreco.2007.03.047

Colding, J., and C. Folke. 1997. The relations among threatened species, their protection, and taboos. Conservation Ecology 1: 6. [online] http://www.ec ologyandsociety.org/vol1/iss1/art6/.

Colding, J. and C. Folke. 2001. Social taboos: "Invisible" systems of local resource management and biological conservation. Ecological Applications 11:584-600.

Comiskey, J., T. Sunderland, and J. SunderlandGroves, editors. 2003. Takamanda: the biodiversity of an African rainforest. Smithsonian Institution, Washington, D.C., USA.

Critchley, W. R. 1968. Final report on Takamanda gorilla survey. Technical report to Winston Churchill Memorial Trust, London, UK.

Egbe, S. E. 2001. The law, communities and wildlife management in Cameroon. Rural Development Forestry Network, Overseas Development Institute, London, UK.
Ekinde, A., M. Ashu, and J. Sunderland-Groves. 2005. Preliminary ape surveys around the Fungom Forest Reserve and Furu-Awa Sub Division, North West Province, Cameroon. Technical report, Wildlife Conservation Society/Cross River Gorilla Project, Limbe, Cameroon.

Etiendem, D. N. 2008. Traditional knowledge on cross river gorilla conservation: a case study in the Bechati-Fossimondi-Besali area, south west Cameroon. Thesis. Human Ecology Department, Vrije Universiteit Brussel, Brussels, Belgium.

Gadgil, M., F. Berkes, and C. Folke. 1993. Indigenous knowledge for biodiversity conservation. Ambio 22:151-156.

Hens, L. 2006. Indigenous knowledge and biodiversity conservation and management in Ghana. Journal of Human Ecology 20(1):21-30.

International Union for the Conservation of Nature (IUCN). 2007. IUCN red list of threatened species. IUCN, Gland, Switzerland. [online] URL: http://w ww.iucnredlist.org.

McFarland, K. L. 2007. Ecology of Cross River gorillas (Gorilla gorilla diehli) on Afi mountain, Cross River State, Nigeria. Dissertation. Graduate Center, City University of New York. New York, New York, USA.

Mittermeier, R. A., J. Wallis, A. B. Rylands, J. U. Ganzhorn, J. F. Oates, E. A. Williamson, E. Palacios, E. W. Heymann, C. M. Kierulff, L. Yongcheng, J. Supriatna, C. Roos, S. Walker, L. Cortes-Ortiz, and C. Schwitzer. 2009. Cross River gorilla (Gorilla gorilla diehli) Matschie, 1904. Primates in peril-the world's 25 most endangered primates 2008-2010. Primate Conservation 22:3841.

Nicholas, A., Y. Warren, S. Bila, A. Ekinde, R. Ikfuingei, and R. Tampie. 2010. Successes in community-based monitoring of Cross River gorillas (Gorilla gorilla diehli) in Cameroon. African Primate 7:55-60.

Nkembi, L., D. N. Etiendem, and A. De Haas. 2006. Lebialem Highlands great apes conservation programme: mid-term technical progress report to 
Forestry Bureau, Taiwan. Environment and Rural Development Foundation (ERuDeF), Menji, Cameroon.

Nyhus, P. J., Sumianto, and R. Tilson. 2003. Wildlife knowledge among migrants in southern Sumatra, Indonesia: implications for conservation. Environmental Conservation 30:192-199. http://dx. doi.org/10.1017/S0376892903000183

Oates, J., R. Bergl, and J. Linder. 2004. Africa's Gulf of Guinea forests: biodiversity patterns and conservation priorities. Advances in Applied Biodiversity Science 6:9-91.

Oates, J., Sunderland-Groves, J., R. D. Bergl, A., A. Nicholas, E. Takang, F. Omeni, I. Imong, R. Fotso, L. Nkembi, and E. Wiliamson. 2007. Regional action plan for the conservation of the Cross River gorilla (Gorilla gorilla diehli). IUCN/ SSC Primate Specialist Group and Conservation International, Arlington, Virginia, USA.

Oates, J. F. 1999. Myth and reality in the rain forest: how conservation strategies are failing in West Africa. University of California Press, Berkeley, California, USA..

Osemeobo, G. R. 1991. Effects of common property resource utilisation on wildlife conservation in Nigeria. GeoJournal 23:241-248. http://dx.doi.org /10.1007/BF00204841

Osemeobo, G. J. 2001. Is traditional ecological knowledge relevant in environmental conservation in Nigeria? International Journal of Sustainable Development and World Ecology 8:203-210. http:/ /dx.doi.org/doi:10.1080/13504500109470077

Rose, L. A., R. A. Mittermeier, O. Langrand, A. Okyeame, and T. M. Butynski. 2003. Consuming nature: a photo essay on African rain forest exploitation. Altisima Press, Palos Verdes Peninsula, Carlifornia, USA.

Saj, T. L., C. Mather, and P. Sicotte. 2006. Traditional taboos in biological conservation: the case of Colobus vellerosus at the Boabeng-Fiema Monkey Sanctuary, Central Ghana. Social Science Information 45:285-307. http://dx.doi.org/10.1177 /0539018406063644

Taah, N. P., L. Miles, and J. Caldecott, editors. 2005. Africa: Republic of Cameroon. Pages 305"313 in J. Caldecott, and L. Mills, editors. World atlas of great apes and their conservation. University of California Press, Los Angeles, California, USA.

Terashima, H. 2001. The relationships among plants, animals and man in the African tropical forest. African Study Monographs Supplementary 27:43-60.

United Nations Convention on Biological Diversity (UNCBD). 2007. Pachamama: a traditional knowledge newsletter of the Convention on Biological Diversity. $C B D$ 1. [online] URL: www. cbd.int/doc/newsletters/news-8j-01-low-en.pdf.

Wright, H. J. 2007. The value and significance of bushmeat to rural communities in the Lebialem Highlands of Cameroon. Thesis. Oxford-Brookes University, Oxford, UK. 
APPENDIX 1. Sample questionnaire

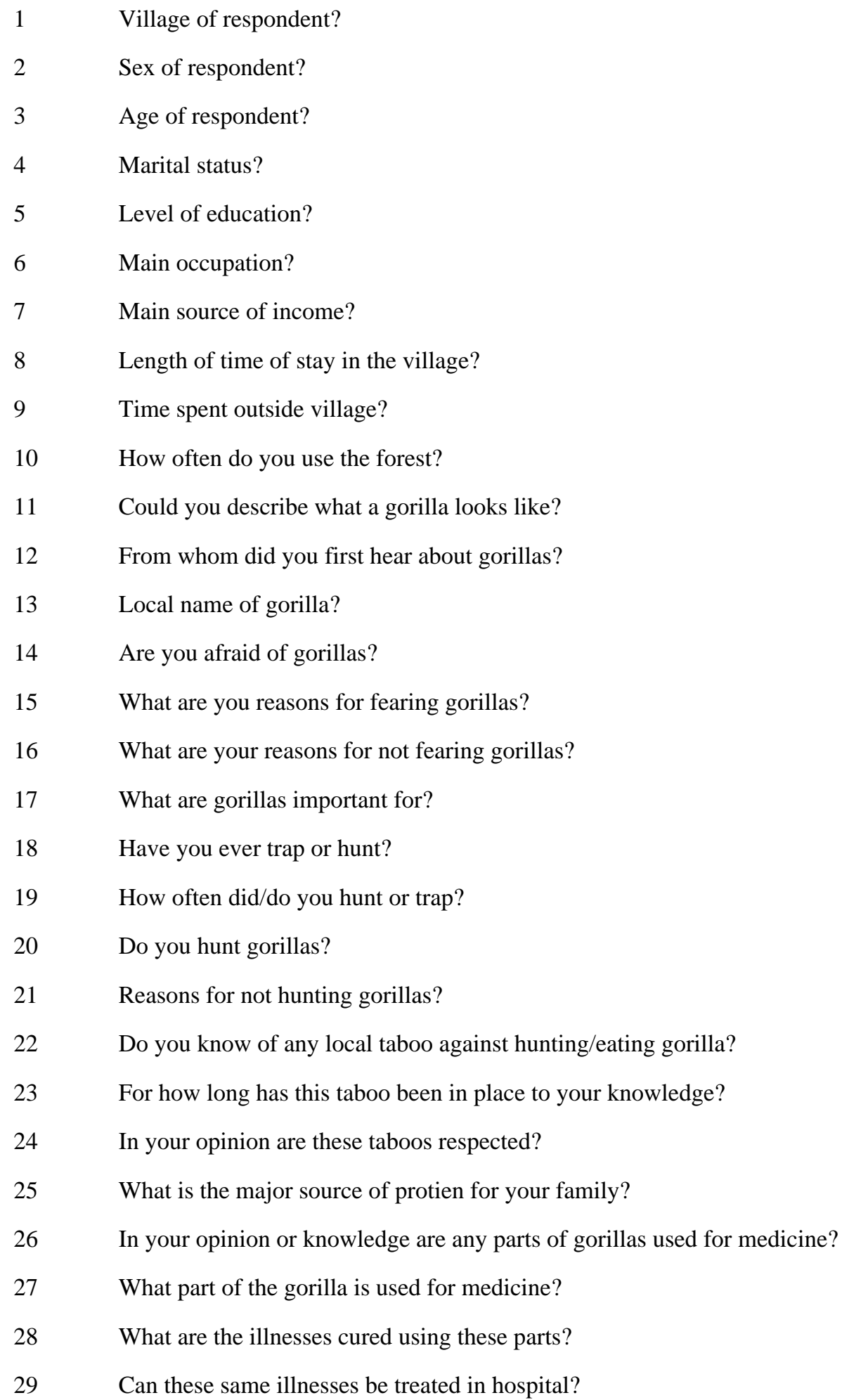


30 If you are sick of any of these diseases will you go to hospital or consult herbalist?

31 How many herbalists do you know who administer this cure?

32 To what extend are these medicine used today compared to the past?

33 In your opinion will gorilla-related medicine be used in the future?

$34 \quad$ Gorillas are totems of village people?

35 To what extent do you agree to the claim that when a gorilla is killed the totem owner dies?

36 To what extent do you agree to the claim that herbalists use gorilla totems to harvest medicinal plants?

37 What is your opinion on the claim that the practice of kinship with gorillas is not good?

38 What is your opinion on the claim that protecting gorillas helps protect people who use gorillas as totems?

39 In your opinion, should we encourage/initiate our children to have/use gorilla totems? 